\title{
Polycythemia Vera, Post-Polycythemic Myelofibrosis Phase
}

National Cancer Institute

\section{Source}

National Cancer Institute. Polycythemia Vera, Post-Polycythemic Myelofibrosis Phase. NCI Thesaurus. Code C41233.

Progression of polycythemia vera characterized by decreased erythropoiesis and granulopoiesis, reticulin and collagen fibrosis of the bone marrow, leucoerythroblastic reaction in the peripheral blood, poikilocytosis, tear-drop shaped red blood cells, and splenomegaly. 